\title{
Waiting time perceptions at transit stops and stations: Effects of basic amenities, gender, and security
}

\author{
Yingling Fan ${ }^{\mathrm{a}, *}$, Andrew Guthrie ${ }^{\mathrm{a}}$, David Levinson ${ }^{\mathrm{b}}$ \\ ${ }^{a}$ Hubert H. Humphrey School of Public Affairs, University of Minnesota, United States \\ ${ }^{\mathrm{b}}$ Department of Civil, Environmental, and Geo-Engineering, University of Minnesota, United States
}

\section{A R T I C L E I N F O}

\section{Article history:}

Received 6 June 2015

Received in revised form 18 January 2016

Accepted 21 April 2016

\section{Keywords:}

Transit

Waiting time

Perception

Amenities

Security

Gender

\begin{abstract}
A B S T R A C T
Waiting time in transit travel is often perceived negatively and high-amenity stops and stations are becoming increasingly popular as strategies for mitigating transit riders' aversion to waiting. However, beyond recent evidence that realtime transit arrival information reduces perceived waiting time, there is limited empirical evidence as to which other specific station and stop amenities can effectively influence user perceptions of waiting time. To address this knowledge gap, the authors conducted a passenger survey and video-recorded waiting passengers at different types of transit stops and stations to investigate differences between survey-reported waiting time and video-recorded actual waiting time. Results from the survey and video observations show that the reported wait time on average is about 1.21 times longer than the observed wait time. Regression analysis was employed to explain the variation in riders' reported waiting time as a function of their objectively observed waiting time, as well as station and stop amenities, weather, time of the day, personal demographics, and trip characteristics. Based on the regression results, most waits at stops with no amenities are perceived at least 1.3 times as long as they actually are. Basic amenities including benches and shelters significantly reduce perceived waiting times. Women waiting for more than $10 \mathrm{~min}$ in perceived insecure surroundings report waits as dramatically longer than they really are, and longer than do men in the same situation. The authors recommend a focus on providing basic amenities at stations and stops as broadly as possible in transit systems, and a particular focus on stops on low-frequency routes and in less safe areas for security measures.
\end{abstract}

(c) 2016 Elsevier Ltd. All rights reserved.

\section{Introduction}

Travel time is an important predictor of mode choice-especially in the developed world, it can even outweigh monetary costs associated with modes, urban form, and personal socio-demographics (Cervero, 2002; Frank et al., 2008). Time, however, can be measured both objectively and subjectively. Objectively, "time is what clocks measure" (Caroll, 2011). Subjectively, time can be perceived and experienced differently based on events (Andersen and Grush, 2009). This brings in a contrasting viewpoint: time can be defined as a fundamental intellectual structure within which humans sequence and compare events (Allison, 2004). Individual perceptions of time can vary significantly from any externally measurable "objective" time (Block, 2014; Fraisse, 1984). Events experienced can either moderate or exacerbate these variations. For example,

\footnotetext{
* Corresponding author at: 301 19th Avenue South, Minneapolis, MN 55455, United States. Tel.: +1 (612) 6262930.

E-mail address: yingling@umn.edu (Y. Fan).
} 
events occurring at regular intervals tend to produce underestimates of objective time, while events occurring at irregular intervals tend to produce overestimates (Yarmey, 2000). Intense experiences-positive or negative-are found to produce overestimates of duration (Angrilli et al., 1997; Ariely and Zakay, 2001; Droit-Volet et al., 2004; Effron et al., 2006). Tipples (2008) specifically found high-arousal experiences with negative emotionality produce greater overestimates of duration than high-arousal experiences with positive emotionality or emotionally neutral experiences. In a transportation context, increasing task complexity (e.g., route complexity) may increase perceived time (Carrion and Levinson, 2013; Parthasarathi et al., 2013).

When it comes to travel times of different modes, public transit faces an inherent disadvantage not shared by other modes: waiting time. Waiting time in transit travel tends to be perceived negatively. Time spent aboard transit vehicles (In-Vehicle Time, or IVT) is generally perceived as taking roughly as long as it really does (Wardman, 1998, 2004). Transit users, however, perceive waits for transit vehicles to arrive as significantly longer than they really are. This phenomenon is commonly expressed in terms of a waiting time multiplier-or the ratio of perceived waiting time to either actual waiting time or in-vehicle time (Wardman, 2014). Auto users similarly overweight stopped time at traffic lights and ramp meters (Levinson et al., 2004; Wu et al., 2009). Negative perceptions of waiting time have negative implications for users' overall feelings about their mode (St-Louis et al., 2014; Tyrinopoulos and Antoniou, 2008; Walle and Steenberghen, 2006), and present a significant obstacle to increasing the competitiveness of public transit, which is more environmental friendly than the private automobile mode (El-Geneidy et al., 2009; Watkins et al., 2011).

Transit agencies increasingly propose high-amenity transit stops and stations for mitigating the perceived burden of waiting time (Denver Union Station Project Authority, 2004; Metropolitan Council, 2012; Transit Planning Board, 2008). However, beyond the amenity of at-stop realtime arrival information (Brakewood et al., 2014, 2015a,b; Dziekan and Kottenhoff, 2007; Gooze et al., 2013; Watkins et al., 2011), existing research does not sufficiently explore how specific station and stop amenities (e.g., benches, shelters) can effectively reduce transit users' perceptions of waiting time. This missing knowledge is problematic for efforts to increase transit use: users' perceptions of transit service play an important role in determining mode choice (Walle and Steenberghen, 2006) and often cannot be determined from common system-level performance measures (Eboli and Mazzulla, 2011). To address this gap in transit planning knowledge, the authors conducted a unique study in the Minneapolis-St Paul (MSP) metropolitan region that combines an onboard survey with video observation to compare transit users' self-reported waiting time with external measures of their actual waiting time. The study takes a uniquely systematic perspective, including a wide range of stop and station types, transit modes, times of day and seasons. We then explain waiting time perceptions as a function of stop/station design and environment. We offer generalizable recommendations that can be applied from a light rail station to a curbside bus stop for reducing perceived waiting times.

\section{Related studies}

Transit users often perceive their waiting time as considerably longer than it actually is. Table 1 summarizes existing research assessing perceived waiting time in comparison with other travel time concepts. These studies found that a minute of perceived waiting time is equivalent to up to $2.5 \mathrm{~min}$ of in-vehicle time (IVT), and is equivalent to $1.2 \mathrm{~min}$ of actual wait time. For example, Wardman (2004) finds that a 2.5:1 ratio of waiting time to in-vehicle time (IVT) is more appropriate for schedule planning and ridership forecasting than the traditional British 2:1 assumption. Horowitz (1981) finds that any wait at all is perceived as equivalent to an extra 8.4 minutes' IVT in a 30 min trip and 13 minutes' IVT in a 45 min trip, and that a ten-minute wait is equivalent to an extra 18.9 or 23.2 min of IVT, respectively.

Waiting time ratios can differ significantly between stated preference (SP; in which participants are asked directly what value they place on waiting time) and revealed preference (RP; in which participants valuations of waiting time are observed from their behavior) data collection protocols: Abrantes and Wardman (2011) found a relatively low ratio of 1.43 among state preference designs, and a considerably higher ratio of 2.32 among revealed preference designs. Wallis et al. (2013) also pointed to a predominance of stated preference designs in interpreting their finding of a low waiting-time ratio of 1.25 in a review of six Australian and one New Zealand studies.

Table 1

Waiting time ratios in existing research.

\begin{tabular}{|c|c|c|}
\hline Study & Ratio & Notes \\
\hline $\begin{array}{l}\text { Dziekan and Kottenhoff } \\
\text { (2007) }\end{array}$ & $1.2: 1$ & $\begin{array}{l}\text { Perceived vs. actual wait time before implementation of realtime info on high-frequency tram line; } 1: 1 \\
\text { after implementation }\end{array}$ \\
\hline Watkins et al. (2011) & $1.2: 1$ & $\begin{array}{l}\text { Perceived vs. actual time in at-stop survey after } \sim 5 \text { min wait time, without realtime transit information } \\
\text { mobile app }\end{array}$ \\
\hline Wardman (1998a) & $1.2: 1-1.7: 1$ & Perceived waiting time vs. perceived IVT \\
\hline Wallis et al. (2013) & $1.3: 1$ & Perceived waiting time vs. perceived IVT; meta-analysis of primarily SP designs \\
\hline Wardman (2013) & $1.5: 1-1.9: 1$ & Perceived waiting time vs. perceived IVT. Varies by trip distance and purpose \\
\hline $\begin{array}{l}\text { Abrantes and Wardman } \\
\text { (2011) }\end{array}$ & $1.4: 1-2.3: 1$ & Perceived waiting time vs. perceived IVT; ratio differs based on SP vs. RP design \\
\hline Horowitz (1981) & $1.9: 1-2.3: 1$ & Perceived waiting time vs. perceived IVT; found non-linear relationship by length of wait and trip \\
\hline Wardman (2004) & $2.5: 1$ & Perceived waiting time vs. perceived IVT \\
\hline
\end{tabular}


Waiting time perceptions may vary depending on circumstances including transit service factors, such as on-time performance (Daskalakis and Stathopoulos, 2008) and service information (Monzon et al., 2013), as well as stop/station factors, such as surroundings, perceived security, and amenities such as enclosed waiting areas, seating or restrooms (Evans et al., 2004; Wardman, 1998a). However, beyond recent evidence that real time arrival information reduces perceived waiting time, there is limited empirical evidence as to which other specific station and stop amenities can effectively influence user perceptions of waiting time.

Globally, the passenger perception influences of transit stop design have received some attention in the literature. Cascetta and Cartenì (2014) found that Napolitan commuters would accept an additional seven minutes of waiting time and ten minutes of access time in order to use a new rail line with markedly more attractive stations than an older line serving similar trips, yet their study did not isolate the impact of specific station and stop amenities. Moreau (1992) found transit users in Grenoble, France tend to overestimate their waiting times overall but that stop design factors such as light, heat/ ventilation and general comfort influence estimates. In a study of Dutch railway passengers, van Hagen (2011) found lighting, music and aesthetics important in shaping perceptions of waiting time, but that stated preferences differ from revealed perceptions: passengers say they prefer bright lighting, calming music and warm colors, but experience waits in dim lighting, with stimulating music and cool colors as taking less time. This result reinforces the importance of directly studying passengers time perceptions as distinct from their stated preferences.

Traveler and trip characteristics can impact waiting time perceptions as well: Psarros et al. (2011) found that old age (of research subjects) and utilitarian trip purposes (i.e. to work, school or personal business) increase Athenian bus users' perceived waiting times by as much as $44 \%$, while a morning departure reduces waiting time perceptions by four percent. Wardman (2013) found higher waiting time ratios for short-distance trips (of which waiting accounts for a greater portion of total trip time), and lower ratios for personal business trips than commute or other trips. General research on transit service quality in Athens and Thessaloniki, Greece, found female transit users are more sensitive to waiting time than male transit users (Tyrinopoulos and Antoniou, 2008).

Despite this existing body of literature, three factors suggest further study of transit stops' wait time perception impacts in a United States context will meaningfully deepen understanding of the relationship: First, wide variability in the quality of U. S. transit stops maximizes the difference between "pleasant" and "unpleasant" waiting environments. Second, wide variability in U. S. street design provisions for pedestrians versus automobiles maximize the importance of transit stops' surroundings in shaping user perceptions. Finally, the low cost and ubiquity of automotive transportation in the U. S. may increase individuals' sensitivity to the quality of experience offered by transit. Yet, existing pertinent research on U. S. (or North American) transit systems is sparse. Diab and El-Geneidy (2014) found average waiting time perception reductions as great as $4.4 \mathrm{~min}$ following a variety of largely schedule reliability-focused improvements (reserved lanes, signal priority, articulated buses, etc.) to a major bus corridor in Montreal, QC, but their study did not focus specifically on stops. Fan and Guthrie (2012), Taylor et al. (2009), as well as Iseki and Taylor (2010) found station and stop characteristics to be important in shaping users' overall perceptions of transit service quality based on stated preference surveys. None of the three studies, however, offer direct, quantitative evidence that amenities can effectively make waiting time during transit trips seem "shorter" to users.

Recent evidence on the effects of providing realtime transit arrival information at stations and stops has been consistent across various cities and regions in the world. Dziekan and Kottenhoff (2007) found that adding realtime arrival information signs to tram stops in The Hauge, The Netherlands reduced perceived waiting times by more than twenty percent based on a longitudinal, before/after survey of passengers. They suggested that realtime arrival information signs improved the experience of using transit as much as reducing headways from ten to eight minutes, at less than one-fifth the cost. Watkins et al. (2011) reached nearly identical results for perceived versus measured waiting time for bus passengers in King County, Washington, USA using an at-stop, in person survey. In a 2014 follow-up study of the King County Metro, Gooze et al. (2013) found continued effects of shortened time perceptions, as well as self-reported more frequent transit use due to realtime information availability by nearly $30 \%$ of respondents. They also find that inaccurate realtime information increases waiting time estimates. Recent studies on the effects of smartphone-based realtime transit arrival information applications find similar results with the effects of electronic realtime information signs. Brakewood et al.'s (2014, 2015b) work on realtime information via mobile devices finds a decrease in reported wait times of (on average) 1-2 min for Boston commuter rail riders and Tampa bus riders who used realtime information apps. In addition, the more heavily-used routes in a New York realtime information pilot program see a median $2.3 \%$ increase in ridership after implementation (Brakewood et al., 2015a).

Methodologically, research on waiting time perceptions includes some form of survey focused on transit passengers. This component is difficult to avoid, as individual perceptions of time-by definition-cannot be externally observed. Most existing research compares perceived waiting time with perceived in-vehicle time (Horowitz, 1981; Wardman, 1998b, 2004). The more recent studies compare perceived waiting time with a direct measurement of actual waiting time (Dziekan and Kottenhoff, 2007; Watkins et al., 2011). Studies comparing perceived waiting time to perceived IVT have the practical data collection advantage of not requiring an external measurement of subjects' actual waiting time, which can significantly simplify data collection. Studies comparing perceived waiting time to actual waiting time offer the ability to compare results based on a standard, external reference point. They also offer a direct focus on the waiting experience, regardless of the quality of in-vehicle experience provided. However, this type of research requires an objective, external measurement of how long subjects actually wait (Dziekan and Kottenhoff, 2007; Reed, 1995; Watkins et al., 2011). 
This research adopts the recently prominent approach of comparing subjects' reported waiting times to external measures of their actual waiting times. We conduct a unique study in which an onboard survey is combined with at-station/ stop video footage to measure participants' subjective and objective lengths of waiting time.

\section{Methods}

The research revolved around comparing transit riders' actual and self-reported waiting times at 36 light rail, commuter rail and bus rapid transit stations, bus transit centers, and curbside bus stops in the MSP metropolitan region, U.S. The MSP region is nicknamed the Twin Cities for its two largest cities: Minneapolis, the largest city in the state of Minnesota, and St. Paul, the state capital. The two downtowns lie roughly $18 \mathrm{~km}$ (11 mi.) apart, surrounded by a variety of urban and suburban neighborhoods. As of 2013 (the year most representative of data collection), the regional transit system was operated by six non-competing transit providers and carried 86.6 million rides on a variety of local and express bus routes, one light rail line, one freeway bus rapid transit line, and one commuter rail line (Metro Transit, 2014; Minnesota Valley Transit Authority, 2015). Data were collected by an onboard survey of transit riders, a series of observations made from video footage of respondents' waiting time, and an audit of station and stop amenities, design characteristics, and surrounding environments. The study area has an extreme climate, particularly in winter-daytime high temperatures during data collection ranged from $-13^{\circ} \mathrm{C}\left(8^{\circ} \mathrm{F}\right)$ to $34^{\circ} \mathrm{C}\left(94^{\circ} \mathrm{F}\right)$. To consider potential impacts of temperature on time perceptions, as found experimentally by Hancock (1993), both summer and winter data were collected. After data collection, regression analyses were performed to examine respondents' reported waiting time as a function of objectively observed waiting time and characteristics of station and stop amenities, while controlling for weather, time of day, self-reported and observed socio-demographic characteristics and trip characteristics.

\subsection{Site selection}

The research team selected 36 data collection sites chosen from a complete list of MSP transit stations and stops. Stratified sampling was used in the site selection process. The first step in the process began with removing all bus stops with fewer than 50 average weekday boardings. This left a total of 703 transit stops and stations. The second step developed a classification schema based upon station/stop types and neighborhood types. Thirty-six sites were selected to ensure representation from each classification. Table 2 illustrates the distribution of study sites by each classification scheme.

As shown in Table 2, these sites offer a full range of amenity levels from full-featured light rail stations to simple curbside bus stops. The sites also provide a mix of urban and suburban locations as well as attractive and unattractive surrounding environments. Transitway stations are the most common individual site type with 13 locations, but are slightly surpassed if all curbside stops (15 locations) are combined. We deliberately include park-and-ride facilities to obtain a comprehensive picture of the transit system, but walk-and-ride stops and stations form a comfortable majority, with 28 of 36 locations. Just over half of all sites are located in commercial, office and/or industrial areas outside of either downtown, partially reflecting the study's focus on high-ridership stops, which tend to be on major thoroughfares. Twenty-one study sites are in one of the central cities, while 15 are in suburbs. Nineteen sites are in neighborhoods with a "low" pleasantness rating, while 17 were in neighborhoods with "Medium" or "High" ratings. To maximize variation, we excluded areas of "medium" pleasantness, with the exception of two suburban transitway stations. We include these due to a lack of suburban transitway stations in areas with "high" pleasantness. Fig. 1 shows locations of study sites in the Twin Cities region, demonstrating the broad urban, suburban and modal distribution of data collection sites.

\subsection{Onboard survey}

The first primary data collection task was a brief survey of Twin Cities transit riders who boarded trains or buses at the 36 study sites. The survey was conducted during July and August, 2013, and February, March and April, 2014. Each site was

Table 2

Distribution of study sites.

\begin{tabular}{|c|c|c|c|c|c|c|c|c|c|}
\hline \multicolumn{2}{|l|}{ Stop type } & \multicolumn{2}{|c|}{ Primary access mode } & \multicolumn{2}{|l|}{ Surrounding land use } & \multicolumn{2}{|c|}{$\begin{array}{l}\text { Neighborhood } \\
\text { location }\end{array}$} & \multicolumn{2}{|c|}{$\begin{array}{l}\text { Neighborhood } \\
\text { pleasantness }\end{array}$} \\
\hline Unimproved curbside & 8 & Park-and-ride & 8 & Commercial/Industrial/Office & 18 & Suburban & 15 & High & 15 \\
\hline Improved curbside & 8 & Walk-up & 28 & Residential & 10 & Urban & 21 & Medium & 2 \\
\hline Transit center & 7 & & & Downtown & 8 & & & Low & 19 \\
\hline Rail/BRT station & 13 & & & & & & & & \\
\hline Total & 36 & Total & 36 & Total & 36 & Total & 36 & Total & 36 \\
\hline
\end{tabular}

Note: Pleasantness ratings were done by a trained researcher via a rough, at-a-glance assessment to speed the selection process. A rough assessment of pleasantness was necessary in the initial site selection process as no comprehensive, metropolitan source of pleasantness data exists. Factors used in pleasantness ratings include sidewalk presence/width, amount and location of off-street parking, tree cover, enclosure of street scenes, architectural variety and ground floor window, etc. 


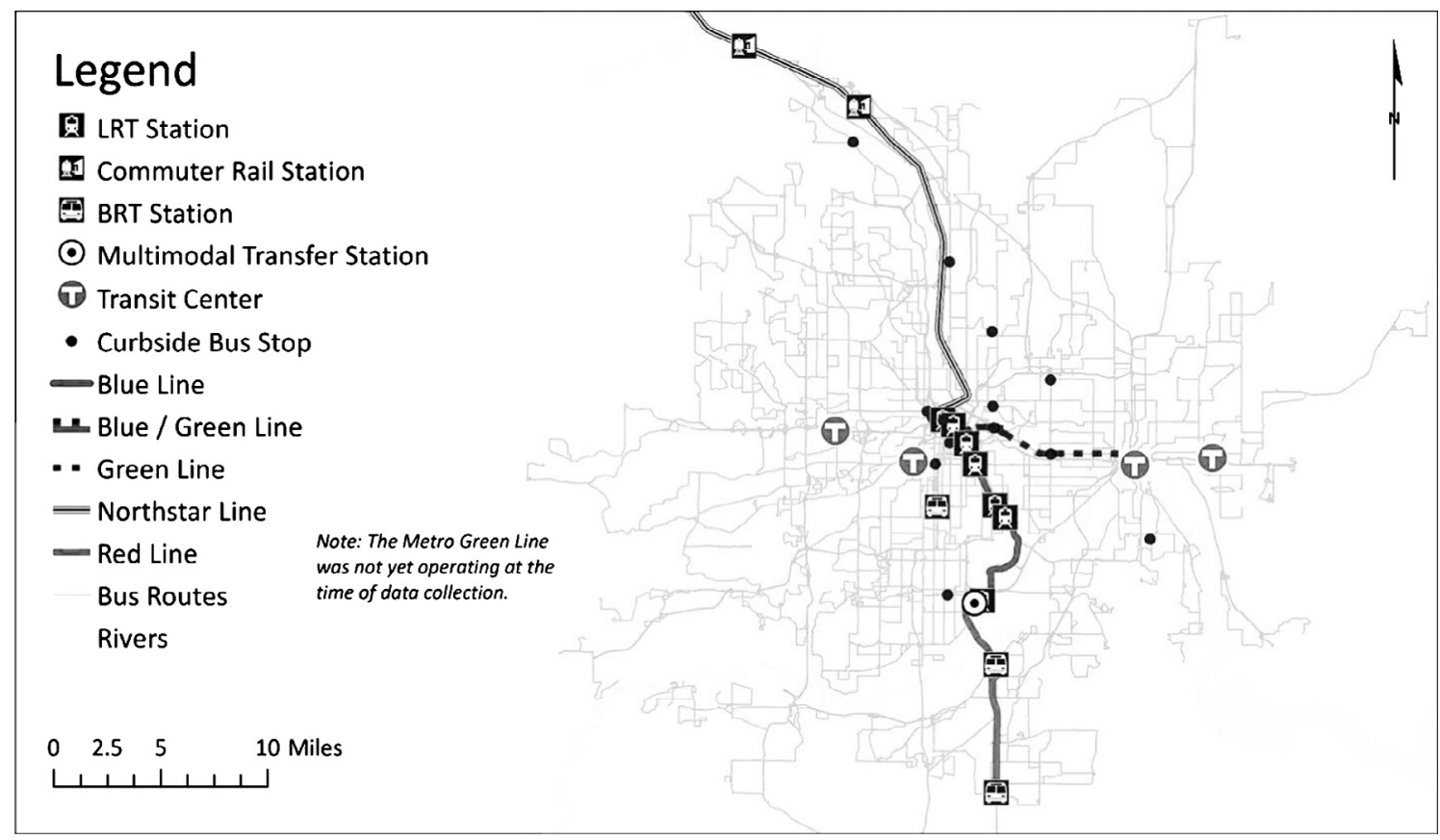

Fig. 1. Study site locations.

surveyed during each of four time periods as defined by Twin Cities Metro Transit: Morning Peak (6:00-9:00 am), Mid-day Off-Peak (9:01 am-2:59 pm), Evening Peak (3:00-6:30 pm) and Late Evening Off-Peak (after 6:30 pm). Survey teams attempted to obtain at least four responses from each site in each time period (sixteen responses per site in total). If they were unsuccessful on the initial visit to a given site at a given time, survey teams made up to two return visits. In some cases, particularly at high-volume locations such as light rail stations, one boarding would yield more than four responses; as a result, some locations have more than the goal of 16 responses.

To allow respondents to complete their entire waiting period as they normally would, recruiting and survey administration took place on board transit vehicles after all passengers had boarded. Survey team members waited unobtrusively at the station/stop, positioned themselves at the back of the boarding queue, and boarded with passengers. Once on board, survey team members recruited as many passengers who had just boarded as possible.

The survey questionnaire began with the key question "How many minutes do you think you waited at the station/stop before you boarded this train/bus?" This question captured the respondent's self-reported waiting time-used as a measure of their perception. The questionnaire was self-administered in writing, and also collected basic information on perceptions of the "pleasantness" of the station/stop, forms of schedule information used (pocket schedules, realtime information app, etc.), approximate trip origin and destination, primary activities at origin and destination, access and planned egress modes, general travel behavior, and basic demographic information.

Upon collecting each completed questionnaire, surveyors (with respondents' permission) took a photograph of each respondent holding up their questionnaire, with a preprinted ID number visible. These photographs enabled the visual identification of respondents without the need to collect any other identifying information such as names.

Self-reported waiting times are not necessarily identical to perceptions of waiting time. However, perceptions, by their very nature, cannot be directly measured. We employ self-reported waiting time as an externally measurable proxy for time perceptions. Our discussion of perceptions in this paper reflects the relationship between reported and actual waiting times.

\subsection{Respondent observations}

The second data collection task involved unobtrusively recording video footage of potential respondents during their wait for the train or bus, and making a series of observations about those who elected to participate from the video. The photographs taken of respondents with their questionnaires were used to connect survey responses with observations, and to assign each set of observations an ID number later used to merge the two data sets. Once a respondent was identified arriving at the station or stop, a researcher recorded the counter time in the video file. During video playback, the researcher made a series of observations about the respondent, including: demographics such as gender, race, and approximate age; manner of dress; items carried; mobility devices, if any; activities engaged in while waiting; and travelling companions, if any. A significant body of research supports the accuracy of at-a-glance estimates of age from photographs (Burt and 
Perrett, 1995; Sörqvist and Erikssön, 2007; Rhodes, 2009) when to-the-year precision (such as for eligibility to purchase alcohol) is not required (George and Hole, 2000). Readily observable respondent characteristics were observed (rather than asked in the questionnaire) to maximize responses by keeping the questionnaire as brief as possible.

Finally, the researchers recorded the counter time at which the respondent boarded the train or bus. The difference between this observation and the initial arrival time observation provided the measure of actual waiting time.

While unusual in research on urban public transit, video observations of individuals while waiting are common in other fields, for example airport design and operations research (Popovic et al., 2009; Wales et al., 2002). Van Hagen (2011) employs a similar protocol with unobtrusive observations while waiting followed by a reflective on board survey to study perceptions of waiting time at railway stations, albeit with in-person observations as opposed to video footage.

\subsection{Waiting environment audit}

To obtain a standardized list of amenities and design features present at data collection sites, as well as information on surrounding environments, the researchers also conducted a waiting environment audit of each data collection site. Based on the common practice of pedestrian environment audits, the audit tool included both quantitative information (identifying the presence/absence/prevalence of features) and qualitative information (identifying the auditor's perception of a given quality using a four-part Likert scale ranging from "Not at all", "Somewhat", "Mostly", to "Very" for each quality). Troped et al. (2006) as well as Millstein et al. (2013) find acceptable inter-rater reliability from similarly designed path and pedestrian environment audits. Specific topics covered by the audit included: the physical layout of the waiting area (separation from surrounding pedestrian flow, boarding from curb vs. transit platform, etc.), shelter provided, seating, other amenities such as water fountains or restrooms, overall physical comfort, route and schedule information provided, maintenance, visual appeal, traffic level, neighborhood security, noise and air quality, and overall perception of pleasantness.

The winter audit also included questions on snow removal. To lessen the influence of individual bias, each site was audited by two members of the research team, one male and one female; each site received the average of both auditors' responses in the final data. Audit data collection was limited to two auditors by budgetary constraints and a need to devote maximum possible resources to the video observation and on-board survey efforts. The use of only two auditors reduces the external validity of the variables derived from the waiting environment audit. In other words, there is no guarantee any other two people would produce the same absolute values. It does less damage to the internal validity of the audit: we can be more confident in the relative values assigned to different sites due to both auditors auditing every site. Finally, the goal of the audit is not to produce an absolute measure of conditions at any one site, nor to approximate the absolute ratings of an average transit user, but to measure the relative difference between sites-a goal served by having both auditors audit every site.

\section{Results}

The survey produced a total of 822 valid responses, for which the respondent was successfully identified in video footage, and for which the questionnaire was substantially complete, including an estimate of waiting time. (For 113 additional survey responses, the respondent could not be conclusively matched with video footage; these responses were not included in the analysis.) Of these 822 responses, our final sample includes 702 observations: the regression models estimated to explain reported waiting time as a function of observed waiting time, stop, respondent and trip characteristics exclude observations with missing values on their variables. Table 3 provides a sample distribution. The sample is, perhaps not surprisingly, composed heavily of population groups likely to use transit, particularly low-income riders, people belonging to minority racial or ethnic groups, and riders without cars. By comparison, 79\% of the Twin Cities metropolitan statistical area was made up of non-Hispanic whites as of the 2010 census, while non-Hispanic whites made up of $59 \%$ of the study sample. In terms of income, only $18 \%$ of metropolitan households had an income less than $\$ 25,000$, while $38 \%$ of the study sample had an income

Table 3

Sample distribution.

\begin{tabular}{llll}
\hline Household income & & Race & \\
\hline$<\$ 25,000$ & $38 \%$ & White, non-Hispanic & $59 \%$ \\
$\$ 25,000-\$ 39,999$ & $18 \%$ & Black & $27 \%$ \\
$\$ 40,000-\$ 59,999$ & $14 \%$ & Hispanic & $5 \%$ \\
$\$ 60,000-\$ 99,999$ & $15 \%$ & Asian & $6 \%$ \\
$\$ 100,000$ or more & $15 \%$ & American Indian & $1 \%$ \\
& & Other & $1 \%$ \\
& & Transit pass & \\
Transit use frequency & & Have: & $63 \%$ \\
$5 x /$ wk or more & $60 \%$ & \\
$2-4 x /$ wk & $19 \%$ & & $41 \%$ \\
$1-4 x /$ mo & $9 \%$ & Car & \\
$<1 \mathrm{x} /$ mo & $8 \%$ & Have: & \\
First time & $4 \%$ & &
\end{tabular}


less than $\$ 25,000$. In terms of auto ownership, $92 \%$ of households in the Twin Cities region had at least one motor vehicle (Minnesota Population Center, 2011), compared to $41 \%$ in the study sample.

Fig. $2 \mathrm{a}$ is a box plot comparing the distribution of reported waiting time to that of actual waiting time. To interpret a box plot, the top of the box represents the 75th percentile, the band inside the box represents the median, and the bottom of the box represents the 25 th percentile. The ends of the whiskers represent the 2 nd percentile and the 98 th percentile. As shown in Fig. 2a, 75\% of respondents have an actual waiting time below $7.5 \mathrm{~min}$ and yet these respondents have a reported waiting time below $10 \mathrm{~min}$. The median value of actual waiting time is $4.5 \mathrm{~min}$ and yet the median of reported waiting time is as high as $5 \mathrm{~min}$. These statistics show that respondents tend to overestimate waiting time.

Fig. $2 \mathrm{~b}$ shows a box plot of the ratio of reported to actual waiting time in five-minute increments of actual waiting time. We choose not to show the ratio for respondents whose actual waiting time was longer than 20 min. This is largely due of the small number of such respondents ( $N=16$, which is $2 \%$ of the final sample). The small number of observations with long actual waiting times is a limitation of this study, but it is also an unavoidable consequence of the practical decision to constrain site selection to stops with relatively high ridership. Stops with relatively high ridership tend to be located on heavilyused routes with relatively frequent service. It is also possible that users of lower frequency routes check schedules more carefully before setting out for their transit trips.

As shown in Fig. 2b, for zero to five minutes of actual waiting time (55\% of the sample), reported waiting time shows a significant trend of over-estimates, with a 25th percentile of 1 , a median of roughly 1.5 , and a 75 th percentile of nearly 2.7 . Estimates tend to be more accurate for longer actual waits: 5-10 min of actual waiting time produces a median ratio close to 1 , though the 75th percentile extends considerably farther from the median than the 25th percentile. Longer actual waits produce slightly underestimated reported waiting time, but as explained earlier, account for only a small percentage of responses.

\subsection{Regression model}

The three data sets from the on-board survey, at-the-stop video observations, and the waiting environment audit were merged and used to estimate a log-log regression model with interaction terms using the equation:

$$
y=\beta_{0}+\beta_{A} * x_{A}+\beta_{2} * x_{2}+\beta_{A 2} * x_{A} * x_{2}+\ldots+\beta_{i} * x_{i}+\beta_{A i} *\left(x_{A} * x_{i}\right) \ldots \beta_{i} * x_{n}+\beta_{A n} *\left(* x_{A} * x_{n}\right)+e
$$

where

$y$ equals the natural logarithm of reported waiting time (with 1 added to the raw variable to avoid losing 0 values),

$x_{A}$ equals the natural logarithm of actual waiting time (also with 1 added), and

$x_{2}$ through $x_{i}$ equal the binary explanatory variables listed below.

Note that variables identified by $\dagger$ below were also interacted with the natural logarithm of actual waiting time (i.e., $x_{A}$ ) to capture the change in its relationship with reported waiting time over actual waiting time. We believe it is theoretically crucial to include interaction terms for some variables because certain explanatory variables likely have different impacts on time perceptions in short and long waits. For example: a bench may have little impact at all on perceptions of a wait so short that a rider faced with it would likely stand anyway, yet may have a profound impact on perceptions of a very long wait. A woman waiting in unsafe surroundings might at first feel relieved at reaching her stop safely, then become increasingly apprehensive as her wait drags on. We do not assume such processes take place, but the use of interaction terms where appropriate allows us to see their effects if they do, an insight the raw variables alone do not offer. While it is true that
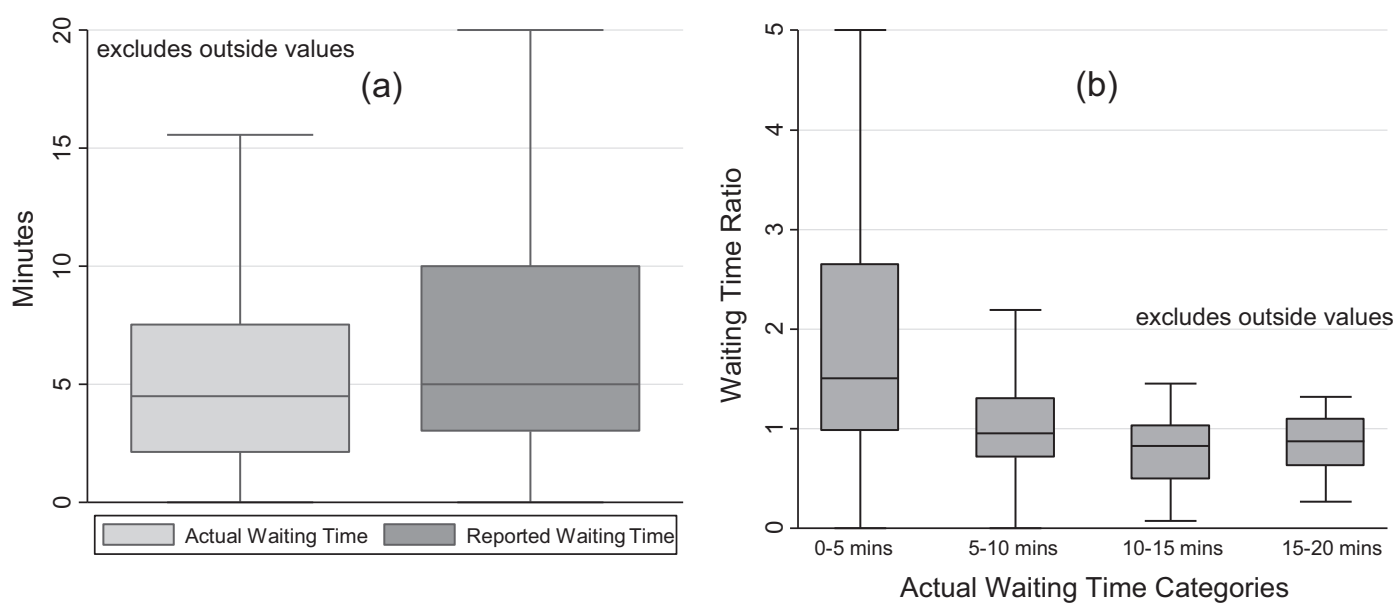

Fig. 2. Box plots comparing Reported and Actual Waiting Times. Note: "Waiting Time Ratio" refers to reported waiting time divided by actual waiting time. 
interaction terms can introduce co-linearity into a regression model, none of the variables in our model correlate strongly enough with each other to raise this issue. In addition, our model is specified from the outset to avoid such problems through the exclusive use of binary variables for the base terms, with the sole exception of the actual waiting time variable.

- Rail $\dagger-\mathrm{A}$ response collected on a light rail or commuter train. Included to account for modal differences in passengers' perceptions.

- Shelter $\dagger-A$ stop or stop/station with some form of shelter provided for waiting passengers. Included as an amenity.

- Bench $\dagger-A$ bench provided as part of the transit station or stop. Included as an amenity.

- Realtime Information Sign $\dagger-$ An electronic display giving passengers realtime transit arrival information. Included due to existing research on time perception impacts of realtime information.

- Female-Female respondent. Included to account for potential gender differences in time perceptions.

- Not/Somewhat Safe-A station or stop rated as "Not safe at all" or "Somewhat safe". Included due to research showing users place high importance on security at transit stations and stops.

- Female \& Not/Somewhat Safe $†-T h e$ interaction of "Female" and "Not/Somewhat Safe". Included to account for gender differences in perceptions of personal security.

- Senior $\dagger-A$ respondent estimated to be 65 years or older. Included to account for generational differences in transit use patterns.

- Minority $\dagger-N o n-w h i t e$ and/or Hispanic respondent. Included to account for cultural differences in transit use and perceptions of transit. (Note: Variables identifying individual minority groups were insignificant in early model runs.)

- Knew Schedule $\dagger-A$ respondent who reported having known the schedule in advance of boarding. Included to account for the potential effects of a known length of wait on time perceptions.

- Transfer-A respondent who arrived at the station or stop by train or bus and transferred to the route he/she was surveyed on. Included due to existing research indicating high perceived disutility of transfers.

- Utilitarian Personal Destination-A respondent who identified the primary activity at their destination as "Personal Business", "Shopping" or any other non-commute destination besides returning home.

- Recreational Destination-A respondent who identified the primary activity at their destination as "Social”, "Recreation" or "Eat Out".

- Mid-Day-A trip made between 9:01 am and 2:59 pm, the mid-day, off-peak service period, as defined by Metro Transit.

- Evening Peak-A trip made between 3:00 pm and 6:30 pm, the evening peak service period, as defined by Metro Transit.

- Late Evening-A trip made after 6:30 pm, the late-evening, off-peak service period, as defined by Metro Transit. Included (along with the two above) to account for potential differences in perceptions of time throughout the service day. "Morning Peak", 6:00 am to 9:00 am, was omitted as the reference.

- Traveled Alone-A respondent who had no traveling companions according to observations made from video footage. Included to account for time perception impacts of solitude versus companionship.

- Activity-A respondent who engaged in some type of activity while waiting other than sitting, standing, looking for the bus, etc. Included to account for the time perception impacts of diversion.

- Winter-A response collected during the winter months. Included to account for weather-linked differences in perceptions.

Early versions of the model also included a binary variable identifying respondents traveling with children as well as interactions between Winter and the station amenity variables. None of these was ever significant. Only 24 respondents were, in fact, travelling with children, likely reducing the explanatory power of the variable. In addition, a long winter period of daytime high temperatures too cold for data collection (less than $-18{ }^{\circ} \mathrm{C}\left[0^{\circ} \mathrm{F}\right]$ ), followed by an unusually rapid spring thaw may have influenced the effects of weather on perceived waiting times.

As shown in Fig. 3a, the raw Reported Waiting Time variable is positively skewed; a natural logarithmic transformation (see Fig. 3b) yields a dependent variable that approaches normal distribution. Early models compared a log-log transformation with a log-level transformation and simple linear regression without transformation. The log-log specification performed best in terms of significant explanatory variables. In addition, log-log coefficients represent elasticities-i.e. percentage changes-significantly easing interpretation.

The raw Actual Waiting Time variable (prior to the logarithmic transformation) has a mean of 6.80 min, with a median of 5 min. Raw values of Actual Waiting Time are shorter as a group, with a mean of 5.64 min and a median of 4.5 min. That is, the reported wait time on average is about 1.21 times longer than the observed wait time, which is consistent with the 1.2 ratio found in prior research as shown in Table 1. All dummy variables except Hi-Frequency, Shelter, Bench, Knew Schedule and Traveled Alone have a mode of zero.

The final model (as shown in the column denoted as "Final" in Table 4) includes 702 observations and achieves an acceptable $R^{2}$ of 0.412 . Besides the final model, Table 4 also presents a simple model excluding interaction terms (shown in the column denoted as "Simplified" in Table 4) and a full model that includes interaction terms for most variables (shown in the column denoted as "Full" in Table 4). As expected, the simple model excluding interaction terms performs significantly worse compared to the full and final models, with a lower $R^{2}$, and notably fewer significant explanatory variables, even considering variables only marginally significant. The final model has an improved adjusted $R^{2}$ compared to the full model. Specifically, the final model removed most insignificant variables from the full model. Two insignificant variables (Bench 
(a)

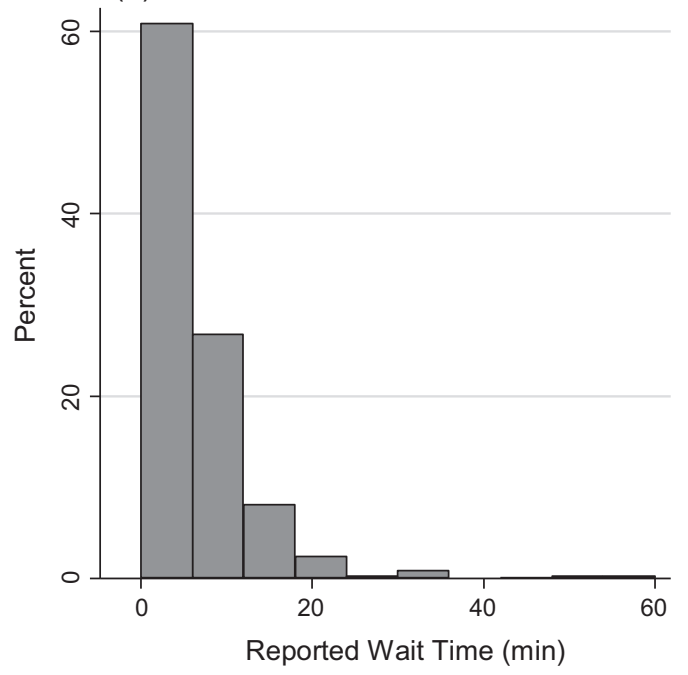

(b)

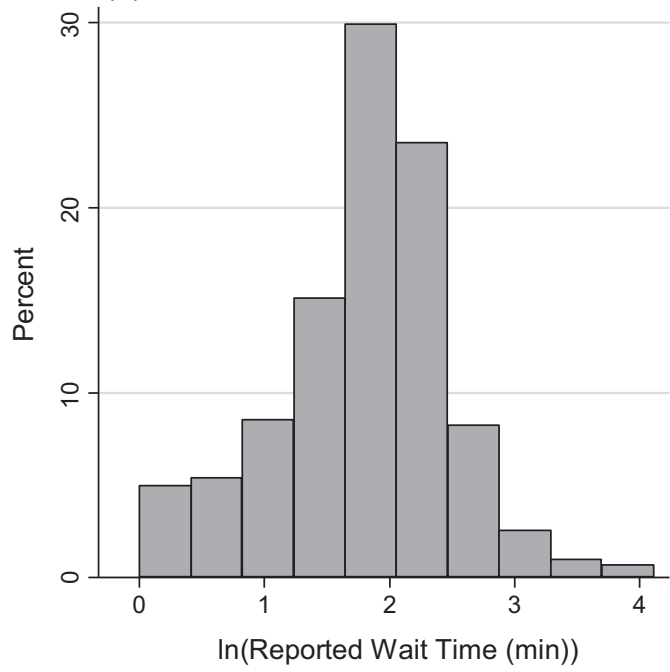

Fig. 3. Histograms of (a) raw and (b) log-transformed reported waiting time.

Table 4

Log-log regression: response variable $\ln$ (Reported Wait).

\begin{tabular}{|c|c|c|c|c|}
\hline & $\begin{array}{l}\text { Response variable: } \\
\text { ln(Reported Wait) } \\
\text { Explanatory variables: }\end{array}$ & $\begin{array}{l}\text { Simple-no interaction } \\
\beta\end{array}$ & $\begin{array}{l}\text { Full } \\
\beta\end{array}$ & $\begin{array}{l}\text { Final } \\
\beta\end{array}$ \\
\hline & ln(Observed Wait) & $0.5481^{* * *}$ & $0.6683^{* * *}$ & $0.6673^{* * *}$ \\
\hline Transit service & $\begin{array}{l}\text { Rail } \\
\text { Rail } * \ln (\text { Observed Wait })\end{array}$ & -0.0755 & $\begin{array}{l}-0.1843 \\
0.0497\end{array}$ & $-0.1039^{*}$ \\
\hline Amenities & $\begin{array}{l}\text { Shelter } \\
\text { Shelter } * \ln \text { (Observed Wait) } \\
\text { Bench } \\
\text { Bench } * \ln \text { (Observed Wait) } \\
\text { Realtime Sign } \\
\text { Realtime Sign } * \ln (\text { Observed Wait) }\end{array}$ & $\begin{array}{l}-0.0666 \\
-0.0551 \\
-0.0909\end{array}$ & $\begin{array}{l}-0.3329^{* *} \\
0.1915^{* *} \\
0.1869 \\
-0.1634^{* *} \\
-0.0844 \\
-0.0039\end{array}$ & $\begin{array}{l}-0.3388^{* *} \\
0.1992^{* *} \\
0.1772 \\
-0.1576^{* *} \\
-0.0920\end{array}$ \\
\hline Respondent characteristics & $\begin{array}{l}\text { Female respondent } \\
\text { Not/somewhat safe } \\
\text { Female } \& \text { not/somewhat safe } \\
\text { Female \& not/somewhat safe } * \ln (\text { Observed Wait) } \\
\text { Senior respondent } \\
\text { Senior Respondent } * \ln (\text { Observed Wait) } \\
\text { Minority } \\
\text { Minority } * \ln (\text { Observed Wait) }\end{array}$ & $\begin{array}{l}0.0126 \\
0.0401\end{array}$ & $\begin{array}{l}0.0057 \\
-0.0273 \\
-0.4038^{* *} \\
0.2166^{* *} \\
0.6376^{* *} \\
-0.3232^{* *} \\
0.4656^{* * *} \\
-0.2539^{* * *}\end{array}$ & $\begin{array}{l}-0.3989^{* * *} \\
0.2049^{* *} \\
0.5871^{* *} \\
-0.3045^{*} \\
0.4454^{* * *} \\
-0.2455^{* * *}\end{array}$ \\
\hline Trip characteristics & $\begin{array}{l}\text { Knew schedule } \\
\text { Knew schedule } * \ln \text { (Observed Wait) } \\
\text { Transferred } \\
\text { Utilitarian personal destination } \\
\text { Recreational destination } \\
\text { Mid-day } \\
\text { Evening peak } \\
\text { Late evening } \\
\text { Traveled alone } \\
\text { Engaged in activity while waiting } \\
\text { Winter }\end{array}$ & $\begin{array}{l}0.1444^{* * *} \\
0.0589 \\
-0.0556 \\
-0.0197 \\
0.2001^{* * *} \\
0.1607^{* * *} \\
0.1358^{*} \\
0.1600^{* * *} \\
0.0128 \\
-0.1114^{* *}\end{array}$ & $\begin{array}{l}0.4486^{* * *} \\
-0.1933^{* * *} \\
0.0871 \\
-0.0803 \\
-0.0372 \\
0.1897^{* * *} \\
0.1650^{* * *} \\
0.1524^{* *} \\
0.1610^{* * *} \\
-0.0248^{* *} \\
-0.0992^{* *}\end{array}$ & $\begin{array}{l}0.1758^{* * *} \\
0.1537^{* * *} \\
0.1410^{*} \\
0.1584^{* * *} \\
-0.0985^{* *}\end{array}$ \\
\hline & Constant & $0.8014^{* * *}$ & $0.5970^{* * *}$ & $0.5686^{* * * *}$ \\
\hline & $\begin{array}{l}N \\
R \text { Square } \\
\text { Adjusted } R \text {-Square }\end{array}$ & $\begin{array}{l}702 \\
0.3765 \\
0.3591\end{array}$ & $\begin{array}{l}702 \\
0.4141 \\
0.3897\end{array}$ & $\begin{array}{l}702 \\
0.4119 \\
0.3938\end{array}$ \\
\hline
\end{tabular}

${ }^{*} p<.1$.

** $p<.05$.

*** $p<.01$ 
and Transfer) are included in the Final model because removing these two insignificant variables results in decrease in the adjusted R-square value. In addition, residual plot from the final model (Fig. 4) shows that residuals of the final model are fairly symmetrically distributed around the zero line in relation to the natural logarithm of actual waiting time (i.e., $x_{A}$ ), indicating good performance of the final model. For these reasons, we base our analysis on the final model, with selected interaction terms included.

As shown in Table 4, the natural logarithm of actual waiting time in the final model is significant and has a positive coefficient, indicating that longer actual waiting times are related to longer reported waiting times. The Rail variable is significant, which indicates that people waiting for rail transit perceive shorter waits compared to people waiting for bus transit. This finding is consistent with prior research (Daskalakis and Stathopoulos, 2008) that service reliability is an important factor of waiting time perceptions (at the time of data collection, the Twin Cities region only had one rail line and the rail line was the most reliable route in the system). Among the station/stop amenities considered, Shelter is significant and negative, though with a positive, significant interaction term, dampening the effect for long waits. Bench is insignificant, but produces a significant, negative interaction, indicating that seating has little initial effect on waiting time perceptions but serves to moderate perceptions of longer waits. Realtime Sign has a negative but insignificant coefficient, which is inconsistent with the existing literature. In the Twin Cities transit system, realtime information signs provide realtime information when available, and default to scheduled arrival times when realtime information is unavailable due to technical difficulties or buses and trains that have yet to start their runs.

Among the respondent characteristics variables, it is particularly notable that the interaction of Female and Not/Somewhat Safe is significant, along with its second-order interaction with $\ln$ (Actual Waiting Time). Minority and its interaction term are significant, with positive base and negative interaction coefficients. Senior Respondent and its interaction is also significant. Among the trip characteristics variables, Mid-day and Evening Peak are significant, with positive coefficients. Interestingly, considering Minnesota weather, Winter is insignificant.

\subsection{Model predictions}

Due to the complexity of the equation produced by a Log-Log model specification with multiple interaction terms, key results are more conveniently interpreted graphically than via the raw regression coefficients. Fig. 5 shows the final model's predictions of Reported Waiting Time under amenity and environment scenarios over values of Actual Waiting Time from zero to $15 \mathrm{~min}$ (95\% of participating responses have an Observed Wait Time of $10 \mathrm{~min}$ or less.)

More specifically, Fig. 5 not only provides mean predictions from the final model but also illustrates the uncertainties surrounding the mean predictions. Statistical software packages including Clarify 2.0 and Stata 13.1 are used to estimate the expected values and their uncertainty (represented in the form of $90 \%$ confidence interval). To make predictions of the base scenarios (i.e., no amenities, male and safe), the named dummy variables (i.e., Shelter, Bench, Female, Unsafe) and their interaction terms are both set equal to zero. To make the predications for the alterative scenarios, the named dummy variables are set equal to one, and their interaction terms are set equal to the natural logarithm of each $x$-axis value shown on the graph, i.e., the product of 1 and $\ln$ (Actual Waiting Time). Unless stated otherwise, all other dummy variables and interaction terms are held at their modal values. Graphed $y$-values are the exponential of the model's prediction of $\ln ($ Reported Waiting Time), with 1 subtracted; they represent the model's prediction of Reported Waiting Time on an arithmetic scale.

Fig. 5a shows model estimates of Reported Waiting Time for the base scenario (no amenities) as well as the scenario with bench and shelter. Specifically, both scenarios predict reported wait times for an 18-64 year old, white male who traveled alone without making transfers in the morning peak time period during summer time and who knew the schedule ahead of time. As shown in Fig. 5a, the base scenario produces a notable overestimate of waiting time. For example, on average a $15 \mathrm{~min}$ wait is perceived as $20 \mathrm{~min}, 10 \mathrm{~min}$ wait perceived as $15 \mathrm{~min}$, and $5 \mathrm{~min}$ wait perceived $10 \mathrm{~min}$. The Shelter and Bench scenario, however, significantly moderate the predicted overestimate, producing 2-3 min of reduction in waiting time perceptions. On average with shelter and bench, a $15 \mathrm{~min}$ wait is perceived as $17 \mathrm{~min}, 10 \mathrm{~min}$ wait perceived as 13 min, and $5 \mathrm{~min}$ wait perceived as $8 \mathrm{~min}$.

Fig. 5b shows the model estimate of reported waiting time based on respondents' gender and perceived security of stop surroundings with no stop amenities. The baseline scenario in Fig. $5 \mathrm{~b}$ is the same as that of Fig. 5a. The mean prediction line

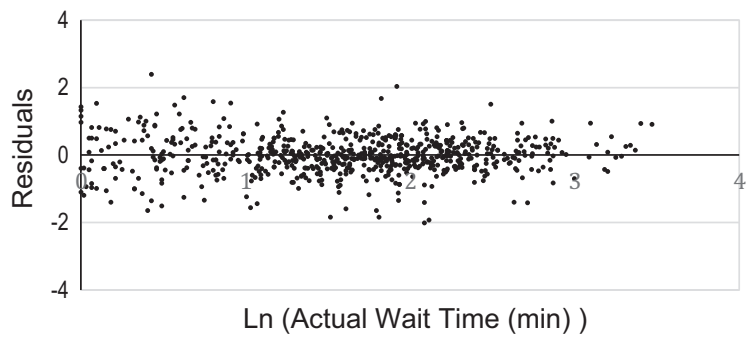

Fig. 4. Residuals vs. log-transformed actual waiting time variable. 

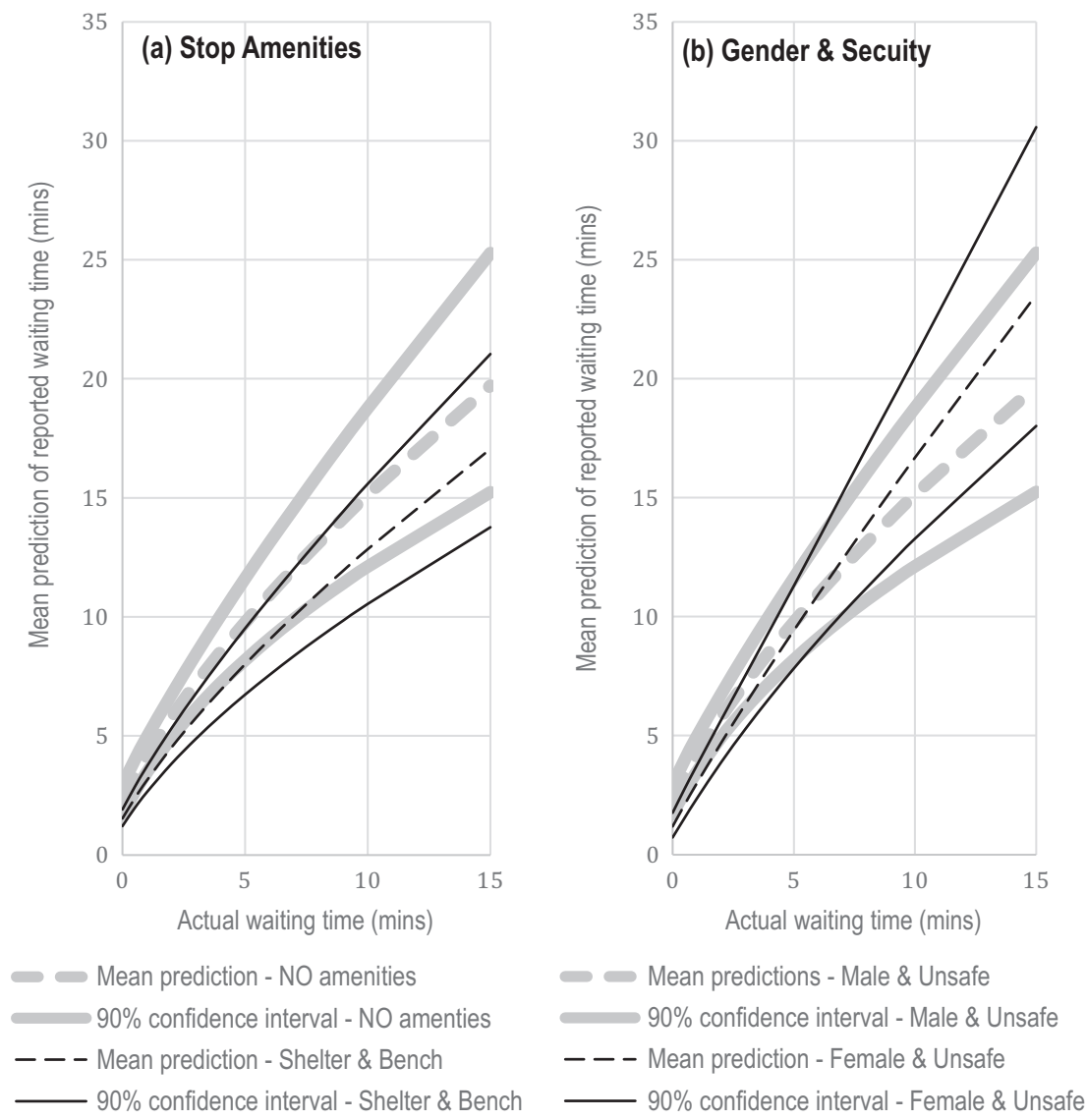

Fig. 5. Model prediction of reported wait time vs. actual waiting time for basic stop amenities and for gender and security.

for a female respondent and a "somewhat safe" or "not safe at all" surrounding environment tracks the baseline mean prediction line fairly closely for the first five minutes of observed waiting time, then diverges increasingly upward. For a woman waiting at a simple "pole-in-the-ground" curbside stop with perceived insecure surroundings, on average a 10 min wait seems to take $17 \mathrm{~min}$, and a $15 \mathrm{~min}$ wait seems to take $24 \mathrm{~min}$.

\section{Conclusions and discussion}

Results from this research support the hypothesis that transit users, on the whole, tend to perceive the time spent waiting for a train or bus as longer than it actually is, and that characteristics of the station or stop and its environment can alter those perceptions. Nonetheless, the study findings show that the relationships between station/stop amenities and waiting time perceptions are more complicated than generally assumed. Our results indicate a non-linear relationship between reported and actual waiting time variables, and that some amenities (e.g., bench) are more important to longer waits than shorter waits.

Our results corroborate existing research on the importance of factors such as time of day (Psarros et al., 2011), passengers' gender (Tyrinopoulos and Antoniou, 2008), surroundings and security (Evans et al., 2004; Wardman, 1998a) in shaping perceptions of waiting time. Existing research also highlights the importance of transit service reliability to passengers' perceptions of waiting time: perceived unreliable services seem to take longer to arrive (Daskalakis and Stathopoulos, 2008). While our study does not directly address service reliability, our final model's finding that rail passengers perceive shorter waits than bus passengers stands to reason in this context, as rail transit provided the most reliable service in the region studied.

Basic amenities (bench and shelter) at the stop/station are associated with significant reductions in reported waiting time. The variables considered do not differentiate between different bench or shelter types or designs-indeed, early attempts to distinguish between "basic" and "premium" shelters found little difference. This conclusion appears to echo the findings of existing stated-preference research on the relative importance of basic station amenities in improving overall transit user experiences (Iseki and Taylor, 2010; Liu et al., 1997). This research provides direct evidence that the broad provision of basic stop amenities can significantly reduce the perceived burden of transit use. 
The insignificance of at-stop realtime information signs goes against the established body of literature on the subject (Dziekan and Kottenhoff, 2007; Gooze et al., 2013; Monzon et al., 2013; Watkins et al., 2011). Existing research specifically on realtime information often adopts a pre-test/post-test design, measuring waiting time perceptions at the same set of stops before and after installation of realtime information signs in the interest of minimizing the influence of other factors. This study differs in seeking the transit stop amenities that best explain variation in passengers' perceived waiting times overall. In addition, specific circumstances in the Twin Cities region at the time of data collection may confound the influence of the realtime sign variable: during data collection, Twin Cities light rail stations (served by the most frequent, reliable transit in the region) did not have functioning realtime information signs. Besides the influences of at-stop realtime information signs, this study is also unable to provide insights into the influences of realtime information via mobile devices or posted schedule information at the stop. Due to respondents' apparent conflation of online schedules and realtime information apps (based on common responses to a question about mobile device use), our survey failed to produce reliable data on the use of "next bus" apps, which may serve as a substitute for realtime signs. In addition, a strong correlation between the presence of a shelter and the presence of a posted schedule prevented the inclusion of posted schedules in the final model. Given the recent evidence that realtime information via mobile devices are effective in reducing waiting time perceptions (Brakewood et al., 2014, 2015a,b), more detailed comparative study of alternative methods for communicating departure information presents a valuable direction for further research. Such research on alternative communication methods will have important policy implications because broad deployment of at-stop realtime information signs often faces cost limitations.

The significance of the minority variable may capture important community-level differences in familiarity with and attitudes toward transit. Alternatively, this variable may be capturing the effects of respondents' income. While the survey questionnaire asked respondents' household income, the response rate to this question was poor compared with others: there were 101 missing values for the observations included in the models. This low response rate prevented explicit inclusion of income in the models. While minority status is certainly not a perfect predictor of low household income, the two are strongly related. Compared non-Hispanic whites and/or high-income individuals, racial/ethnic minority groups and lowincome individuals have relatively high transit use rates and may be less likely to associate social stigma with transit use. These differences may be responsible for shorter perceptions of waiting time. If true, this situation speaks to the importance of social perceptions in shaping the experience of transit use.

Finally, the stark difference between the baseline and Female Respondent in Unsafe Environment scenarios points to an important direction for improving the transit experience of female users. In the region studied, women account for a majority of transit commutes (United States Bureau of the Census, 2014). It appears that, in unsafe locations, women's experience of waiting for a train or a bus differs substantially from men's. The long reported waits for women in unsafe or somewhat safe environments appear to indicate a needlessly stressful passenger experience which is unlikely to help ridership. Perceptions of personal security in some locations may impede female choice riders from relying on transit. Further qualitative study may be warranted to determine specific issues such as fear of crime, street harassment, etc. Still, focusing on basic security improvements around less-safe transit stops appears to be an important gender equity measure, and one with the potential for significant returns in terms of reducing gender gap in perceived waiting times.

To summarize, the results of this analysis indicate the potential for transit stations and stops, and the waiting environments they create, to significantly influence passengers' perceptions of waiting time. In particular, they point to the importance of providing basic amenities where possible, as well as the importance of increasing perceptions of personal security around the least safe stops, particularly from the perspective of female passengers. The topics of stop amenities, gender, security, and waiting time merits more tightly focused research.

\section{Funding disclosure}

The Transitway Impacts Research Program of the University of Minnesota's Center for Transportation Studies provided funding for the research; the program's Technical Advisory Group members provided technical assistance and data used in study site selection. This was the extent of funders' involvement in the research.

\section{References}

Abrantes, P., Wardman, M., 2011. Meta-analysis of U. K. values of time: an update. Transport. Res., Part A: Policy Pract. 45 (1), 1-17.

Allison, H., 2004. Kant's Trancendental Idealism. Yale University Press.

Andersen, H.K., Grush, R., 2009. A brief history of time-consciousness: historical precursors to James and Husserl. J. History Philos. 47 (2), $277-307$.

Angrilli, A., Cherubini, P., Pavese, A., Manfredini, S., 1997. The influence of affective factors on time perception. Percept. Psychophys. 59, $972-982$.

Ariely, D., Zakay, D., 2001. A timely account of the role of duration in decision making. Acta Psychol. 108 (2), $187-207$.

Block, R.A., 2014. Cognitive Models of Psychological Time. Psychology Press.

Brakewood, C., Barbeau, S., Watkins, K., 2014. An experiment evaluating the impacts of real-time transit information on bus riders in Tampa, Florida. Transport. Res. Part A: Policy Pract. 69, 409-422.

Brakewood, C., Macfarlane, G.S., Watkins, K., 2015a. The impact of real-time information on bus ridership in New York City. Transport. Res. Part C: Emerg. Technol. 53, 59-75.

Brakewood, C., Rojas, F., Zegras, C., Watkins, K., Robin, J., 2015b. An analysis of commuter rail real-time information in boston. J. Public Transport. 18 (1), 1 20.

Burt, D.M., Perrett, D.I., 1995. Perception of age in adult Caucasian male faces: computer graphic manipulation of shape and colour information. Proc. R. Soc. Lond. B Biol. Sci. 259, 137-143. 
Caroll, S., 2011. From Eternity to Here: The Quest for the Ultimate Theory of Time. Oneworld Publications.

Carrion, C., Levinson, D., 2013. Uncovering the influence of commuters' perception on the reliability ratio. In: 92nd Annual Meeting of the Transportation Research Board, Washington, D. C.

Cascetta, E., Cartenì, A., 2014. The hedonic value of railways terminals. A quantitative analysis of the impact of stations quality on travellers behaviour. Transport. Res. Part A: Policy Pract. 61, 41-52.

Cervero, R., 2002. Built environments and mode choice: toward a normative framework. Transport. Res. Part D: Transp. Environ. 7 (4), $265-284$.

Daskalakis, N.G., Stathopoulos, A., 2008. Users' perceptive evaluation of bus arrival time deviations in stochastic networks. J. Public Transport. 11 (4), $25-38$. Denver Union Station Project Authority, 2004. Denver Union Station Master Plan. Denver Union Station Project Authority, Denver.

Diab, E.I., El-Geneidy, A.M., 2014. Transitory optimism: changes in passenger perception following bus service improvement over time. Transport. Res. Rec.: J. Transport. Res. Board 2415 (1), 97-106.

Droit-Volet, S., Brunot, S., Niedenthal, P.M., 2004. Perception of the duration of emotional events. Cogn. Emot. 18, 849-858.

Dziekan, K., Kottenhoff, K., 2007. Dynamic at-stop real-time information displays for public transport: effect on customers. Tranpost. Res. Part A 41, 489501.

Eboli, L., Mazzulla, G., 2011. A methodology for evaluating transit service quality based on subjective and objective measures from the passenger's point of view. Transp. Policy 18, 172-181.

Effron, D.A., Niedenthal, P.M., Gil, S., Droit-Volet, S., 2006. Embodied temporal perception of emotion. Emotion 6, 1-9.

El-Geneidy, A.M., Hourdos, J., Horning, J., 2009. Bus transit service planning and operations in a competitive environment. J. Public Transport. 12 (3), 39-59.

Evans, J., Pratt, R., Texas Transportation Institute, Jay Evans Consulting LLC, Parsons Brinkerhoff Quade \& Douglas Inc, Cambridge Systematics, K. T. Analytics, I., 2004. Traveler Response to Transportation System Changes: Chapter 9-Transit Scheduling and Frequency. (No. 95). Transit Cooperative Research Program; Washington, D. C.

Fan, Y., Guthrie, A., 2012. Assessing Neighborhood and Social Influences of Transit Corridors. (Final Report No. CTS 12-19). University of Minnesota, Twin Cities: Center for Transportation Studies.

Fraisse, P., 1984. Perception and estimation of time. Annu. Rev. Psychol. 35 (1), 1-37.

Frank, L., Bradley, M., Kavage, S., Chapman, J., Lawton, T., 2008. Urban form, travel time, and cost relationships with tour complexity and mode choice. Transportation 35 (1), 37-54.

George, P.A., Hole, G.J., 2000. The role of spatial and surface cues in the age-processing of unfamiliar faces. Visual Cognition 7, 485-509.

Gooze, A., Watkins, K.E., Borning, A., 2013. Benefits of real-time transit information and impacts of data accuracy on rider experience. Transport. Res. Rec.: J. Transport. Res. Board 2351 (1), 95-103.

Hancock, P.A., 1993. Body temperature influence on time perception. J. Gen. Psychol. 120 (3), 197-216.

Horowitz, A., 1981. Subjective value of time in bus transit travel. Transportation 10, 149-164.

Iseki, H., Taylor, B., 2010. Style versus service? An analysis of user perceptions of transit stops and stations. J. Public Transport. 13 (3), $23-48$.

Levinson, D., Harder, K., Bloomfield, J., Winiarczyk, K., 2004. Weighting waiting: evaluating the perception of in-vehicle travel time under moving and stopped conditions. Transport. Res. Rec.: J. Transport. Res. Board 1898, 61-68.

Liu, R., Pendyala, R., Polzin, S., 1997. Assessment of intermodal transfer penalties using stated preference data. Transport. Res. Rec.: J. Transport. Res. Board 1607, 74-80.

Metro Transit, 2014. 2013 Facts. Retrieved from <http://www.metrotransit.org/Data/Sites/1/media/about/facts/2013/2013_metrotransit_facts.pdf>.

Metropolitan Council, 2012. Regional Transitway Guidelines: Twin Cities Region. (No. 35-12-006). Twin Cities Metropolitan Council, Saint Paul.

Millstein, R., Cain, K., Sallis, J., Conway, T., Geremia, C., Frank, L., Saelens, B., 2013. Development, scoring, and reliability of the Microscale Audit of Pedestrian Streetscapes (MAPS). BMC Public Health 13, 403-418.

Minnesota Population Center, 2011. National Historical Geographic Information System: Version 2.0. University of Minnesota, Minneapolis, MN.

Minnesota Valley Transit Authority, 2015. Suburban Transit Association Update. Retrieved from <http://www.mvta.com/cms-files/sta_update_03_25_15. pdf>.

Monzon, A., Hernandez, S., Cascajo, R., 2013. Quality of bus services performance: benefits of real time passenger information systems. Transp. Telecommun. 14 (2), 155-166.

Moreau, A., 1992. Public transport waiting times as experienced by customers. Public Transp. Int. 41 (3), $52-71$.

Parthasarathi, P., Levinson, D., Hochmair, H., 2013. Network structure and travel time perception. PLoS ONE 8 (10), e77718.

Popovic, V., Kraal, B., Kirk, P., 2009. Passenger experience in an airport: an activity-centred approach. In: IASDR 2009 Proceedings, Paper presented at the Korean Society of Design Science, COEX, Seoul, 18-22 September, pp. 1-10.

Psarros, I., Kepaptsoglou, K., Karlaftis, M., 2011. An empirical investigation of passenger wait time perceptions using hazard-based duration models. J. Public Transport. 14 (3), 109-122.

Reed, T., 1995. Reduction in the burden of waiting for public transit due to real-time schedule information: a conjoint analysis study. In: Vehicle Navigation and Information Systems Conference, pp. 83-89.

Rhodes, M.G., 2009. Age estimation of faces: a review. Appl. Cognitive Psychol. 23, 1-12.

Sörqvist, P., Erikssön, M., 2007. Effects of training on age estimation. Appl. Cognitive Psychol. 21, 131-135.

St-Louis, E., Manaugh, K., van Lierop, D., El-Geneidy, A., 2014. The happy commuter: a comparison of commuter satisfaction across modes. Transport. Res. Part F: Traffic Psychol. Behav. 26 (Part A(0)), 160-170.

Taylor, B., Iseki, H., Miller, M., Smart, M., 2009. Thinking outside the bus: Understanding user perceptions of waiting and transferring in order to increase transit use California PATH Program, Institute of Transportation Studies, University of California at Berkeley.

Tipples, J., 2008. Negative emotionality influences the effects of emotion on time perception. Emotion 8 (1), $127-131$.

Transit Planning Board, 2008. Concept 3: Creating and Realizing the Regional Transit Vision. (Final Technical Report). Atlanta Regional Commission, Atlanta.

Troped, P., Cromley, E., Fragala, M., Melly, S., Hasbrouck, H., Gortmaker, S., Brownson, R., 2006. Development and reliability and validity testing of an audit tool for trail/path characteristics: the path environment audit tool (PEAT). J. Phys. Act. Health 3 (S1), S158-S175.

Tyrinopoulos, Y., Antoniou, C., 2008. Public transit user satisfaction: variability and policy implications. Transp. Policy 15, $206-272$.

United States Bureau of the Census, 2014. Commuting Characteristics by Sex: 2010-2012 American Community Survey 3-Years Estimates. Retrieved from <http://factfinder2.census.gov/faces/tableservices/jsf/pages/productview.xhtml?pid=ACS_12_3YR_S0801\&prodType=table>.

van Hagen, M., 2011. Waiting Experience at Train Stations [Doctoral dissertation]. Eburon Uitgeverij BV.

Wales, R., O’Niell, J., Mirmalek, Z., 2002. Ethnography, customers and negotiated interactions at the airport. IEEE Intell. Syst. 17 (5), 15-23.

Walle, S., Steenberghen, T., 2006. Space and time related determinants of public transport use in trip chains. Transport. Res. Part A: Policy Pract. 40 (2), $151-$ 162.

Wallis, I., Lawrence, A., Douglas, N., 2013. Economic Appraisal of Public Transport Service Enhancement. Research Report 533, New Zealand Transport Agency.

Wardman, M., 1998a. A Review of British Evidence on the Valuations of Time and Service Quality. Department of the Environment, Transport and the Regions, Leeds.

Wardman, M., 1998b. The value of travel time: a review of British evidence. J. Transp. Econom. Policy 32 (3), $285-316$.

Wardman, M., 2004. Public transport values of time. Transp. Policy 11 (4), 363-377.

Wardman, M., 2013. Value of time multipliers: a review and meta-analysis of European-wide evidence. In: TRB 92nd Annual Meeting Compendium of Papers. Paper presented at the 92nd Annual Meeting of the Transportation Research Board, Washington, DC, 13-17 January, pp. 1-18.

Wardman, M., 2014. Valuing Convenience in Public Transport: Roundtable Summary and Conclusions [White paper]. International Transport Forum, Paris. 
Watkins, K., Ferris, B., Borning, A., Rutherford, G., Layton, D., 2011. Where Is My Bus? Impact of mobile real-time information on the perceived and actual wait time of transit riders. Transport. Res. Part A: Policy Pract. 45 (8), 839-848.

Wu, X., Levinson, D., Liu, H., 2009. Perception of waiting time at signalized intersections. Transport. Res. Rec.: J. Transport. Res. Board 2135, 52-59.

Yarmey, A.D., 2000. Retrospective duration estimations for variant and invariant events in field situations. Appl. Cognitive Psychol. 14 (1), $45-57$. 